\title{
ACTIVATING LARGE LECTURE FINANCIAL LEARNING: COLLABORATION AND CLICKERS DURING COVID-19
}

Dan W. ROYER ${ }^{1 *}$

Olga MCATEE ${ }^{2}$

\begin{abstract}
Received: July 2021 | Accepted: August 2021 | Published: August 2021
Please cite this paper as: Royer, D.W., Mcatee,O. (2021) Activating large lecture financial learning collaboration and clickers during Covid-19, Holistica Journal of Business and Public

Administration, Vol. 12, Iss. 2, pp.49-63
\end{abstract}

\begin{abstract}
This paper examines our approach to teaching a large-lecture personal finance course promoting students' financial literacy. We identify the context of this course, including the rationale for largeenrolment courses and issues with the format in general, describing how using clickers and active learning strategies results in increased engagement, attendance, and critical thinking. Learning outcomes designed to support student formation of both internal and external views of finance are holistic and expansive, broader than measures of wealth accumulation alone. Moreover, a strategic initiative focused on career readiness aligns specific competencies with course content focused on developing transferrable skills through practical, real-world examples designed to engage problemsolving and critical thinking. This pragmatic and practical focus linked these transferable skills to a framework of learning grounded in the twin concepts of financial capability and competency. Additionally, we address how Covid-19 disrupted these courses, detailing adjustments necessitated by the new reality of social distancing while adjusting our approach to student participation as we met simultaneously in face-to-face and synchronous Zoom sessions. We concluded that additional considerations must include equitable access to resources based on our pandemic experience. Future research should examine these adjustments in light of developing culturally responsive methods to promote equitable learning.

Keywords: Financial Literacy; Large-Lecture; Clickers; Covid-19; Remote Teaching
\end{abstract}

\section{Introduction}

The purpose of this scholarly paper is to examine our approach to teaching a large-lecture personal finance course promoting student financial literacy. We utilize clickers and active learning strategies to engage basic financial concepts that inform financial behaviour, help

\footnotetext{
${ }^{1}$ Accounting Lecturer in the Paul W. Parkison Department of Accounting at Ball State University, USA, email:dwroyer@bsu.edu.

* Corresponding author.

${ }^{2}$ Finance Lecturer in the Department of Finance and Insurance at Ball State University, USA, email: osmcatee@bsu.edu.
} 


\section{HOLISTICA Vol 12, Issue 2, 2021, pp.49-63}

students avoid potential financial exploitation (Karger, 2015), and develop financially informed citizens (Willis, 2017). Retzmann and Seeber (2016) propose a model of financial competencies encompassing three domains: (a) decision-making and rationality (making rational decisions between financial alternatives), (b) relationship and interaction (the social context of economic interaction), and (c) system and order (discerning economic interrelationships that are systemic).

Rather than competencies, the Personal Finance Education Group [PFEG] (n.d.) described financial capability conceived in democracy and justice (fairness), critical thinking and inquiry (encountering different ideas and opinions) and taking informed and responsible action (taking action on problems). These conceptions of financial literacy focus on both the internal view of finance (related to knowledge and perceptions) alongside an exterior view that is observable in financial behaviours. Financial literacy from an internal view encompasses a psychological perspective (Loerwald and Stemann, 2016), metacognition (Antionietti et al., 2016), developmental and social norms (Marchetti et al., 2016), and a critically compassionate approach (Lucey, 2018). An external view of financial literacy includes competencies (Retzmann \& Seeber, 2016), financial behaviour (Henager \& Cude, 2016), and a sociological perspective (Henchoz, 2016). Using both the interior and exterior view results in an expanded understanding of financial literacy in a more holistic framework.

Lucey (2018) resisted a definition of financial literacy based on wealth accumulation alone and proposed grounding understanding in a critically compassionate approach instead. This approach employs qualitative considerations for others and self in the act of financial decision-making, concluding that empathy demands a compassionate response in difficult financial conditions. A critically compassionate approach to financial literacy opposes traditional wealth accumulation models based on social conventions that include selfishness, control, and manipulation. Therefore, it questions connecting a sense of self with net worth, recognizing that material resources alone fail to provide a sustainable sense of self-worth (Lucey, 2018).

The traditional focus on financial products leads to managing and allocating financial assets to accumulate personal financial wealth, resulting in financial distancing. Hence, caring for neighbours and community are secondary considerations to personal wealth accumulation. Applying a traditional frame of reference attributes financial difficulties solely to individual decision-making failures. Such an approach lacks sensitivity to embedded social structures that perpetuate disparities based on socioeconomic status.

However, Covid-19 imposed two crises: an unparalleled threat to public health and the halting of the economic activity. We recognize the tenuousness of financial resources when significant sectors of the economy close in response to the virus threat. We argue that it is critically important to understand that financial resources are not an adequate measure of self-worth in such a context. Instead, self-worth originates from an environment of care, safety, and acceptance, regardless of financial resources. Henchoz (2016) argued that financial literacy education, to be effective and empowering, "must 
HOLISTICA Vol 12, Issue 2, 2021, pp.49-63

become anchored in the relevant social and relational framework, which means they must develop an educational approach going beyond individual skills and shortcomings" (p.109).

We examine our approach to a financial literacy class considering the stated goals of (a) developing financial competencies and capability, (b) informing financial behaviour, and (c) motivating students to become financially informed citizens in the context of a largelecture course impacted by the Covid-19 pandemic. We frame our discussion conceptually through competencies that expand financial capability and financial literacy (Figure 1).

Figure 1 The conceptual model for this paper

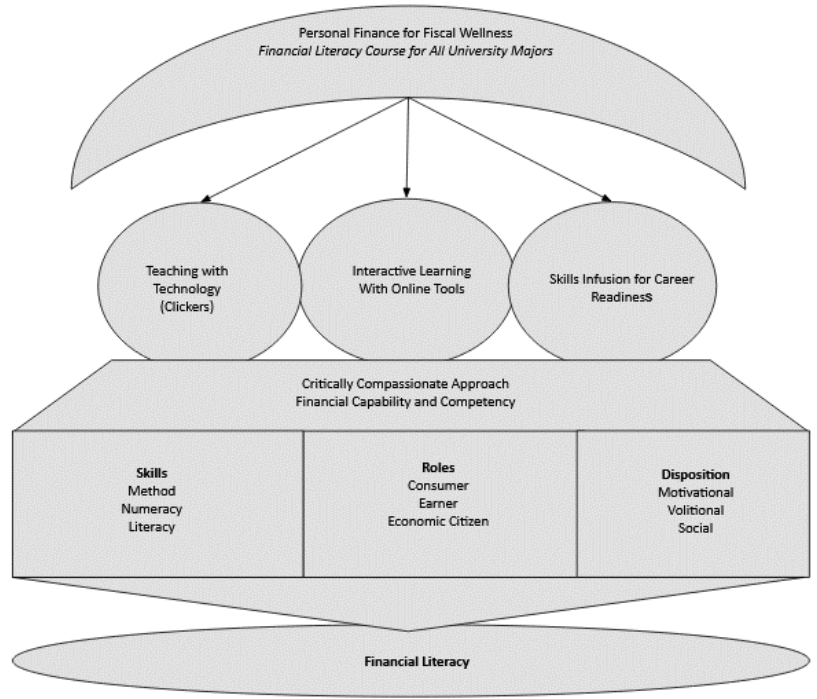

Source: Authors' synthesis, 2021.

Next, we consider this framework in the context of the university-wide core course in personal finance required for all students.

\section{Context}

The course delivered in a large lecture format is called Personal Finance for Fiscal Wellness. Typically, each section includes between 135 and 250 students and is one semester credit hour. In this course, we utilize a student response system, referred to generically as clickers, to improve student interaction. This technology allows faculty to pose questions throughout the lecture, as students respond privately. Individual student responses are collected, aggregated, summarized, and visualized for the class while protecting individual privacy. This technology provides opportunities for low-risk student interaction with lecture content, increasing student participation. 
Course content is a collection of personal finance topics relevant to the needs of young adults, including (a) the interior finance point of view, (b) budgeting, financial tools, and compound growth, (c) income management, (d) taxation, (e) banking, checking accounts, credit, (f) loans and housing, (g) savings, (h) investments, (i) Insurance and risk, and (j) retirement planning. The structure of these topics is in the form of a financial life journey. We begin with an interior view of finance to address college students' financial literacy perspectives and needs. Additional topics related to an interior view include goal setting, time horizons, investing, and how they work together to provide adequate retirement savings. We adapt these crucial topics considering student interests and everyday experiences (Koh, 2016). Beck and Neiser (2009) argued that contextualizing the financial situations college students face is critical to effective financial literacy education. We argue that combining an audience response system (clickers), collaborating with a credit union, and assigning podcast reflections related to current events and issues infuse relevance in the topics, encouraging student engagement.

\subsection{Issues with large lecture format}

Large lecture format classes provide scheduling alternatives, maximize efficiency and faculty productivity while minimizing costs. In our review of the literature, a sampling of large lecture courses included an introductory Management Information Systems class enrolling approximately 150 students per section (Nelson \& Hauck, 2008), a Biology course for non-majors enrolling 100-300 students per section (El-Rady, 2006), a large lecture basic communication course with 300-600 students per section (Denker, 2013), and a marketing class enrolling over 600 students (Dean et al., 2017). In this array of large enrolment courses, we identified issues crossing disciplinary boundaries, impacting pedagogical practice, and providing a rationale for clickers in a university-wide personal finance course.

Issues occur in large enrolment courses because of the nature of the content (required) along with the broad range of students enrolled. Students who are non-majors often lack the motivation to attend class sessions or ask questions (El-Rady, 2006; Nelson \& Hauck). Dean et al. (2017) argued: "the feeling of anonymity creates impersonal, disengaged, unmotivated, and passive learning environments" (p. 6). Moreover, Denker (2013) identified an issue with these courses when faculty are physically and affectively distanced from students, while students take on the role of passive observer, thereby reducing attendance, limiting engagement, and effectively impeding the level of critical thinking. In an attempt to increase student engagement and improve student interaction, we address using clickers in our large lecture finance course.

\section{Introducing an audience response system (clickers)}

In these classes, we utilized an audience response system (ARS), more commonly called clickers. These systems include small hand-held remotes for students, a receiver base, and software to record responses (Caldwell, 2007). We utilized clickers to interact with 
students through a series of questions interspersed in the lecture. These questions serve multiple purposes, including (a) interacting with peers, (b) assessing student comprehension, (c) guiding thinking, (d) reviewing concepts, and (e) introducing active learning. Also, using this technology allows us to make changes to the typically passive role of students in a one-way lecture. Questioning students is not new, but the ability for students to respond anonymously avoids the risk and shame associated with incorrect responses in front of peers.

Constructing good clicker questions rooted in pedagogy and practicality is vital for student engagement (Thomas \& Dougall, 2019). Well-crafted questions asked in a precise order provide students the opportunity to synthesize information and develop analytical skills. Additionally, effectively using questions to bridge pre-lecture and lecture time increases participation, informs instructors about student comprehension, and facilitates discussion (Vazquez \& Chiang, 2020). A variety of polling questions also help instructors construct an effective learning environment to improve key retention indicators. In our financial literacy course, we utilize clicker questions to increase interaction, provide formative assessment, guide thinking and make lectures fun (Caldwell, 2007).

\subsection{Financial literacy focus and learning outcomes}

Students learn about specific financial content in this course, including the affective (interior view) and skill development (exterior view). Utilizing the interior view, students explore concepts that lead to forming a financial outlook. These include risk management, developing human capital through education, the importance of social capital, and an individual psychological time perspective. In contrast, the exterior view attends to behaviour and skill development needed to execute financial decision-making.

Our approach in this course is pragmatic, including the socially constructed, non-cognitive elements in concert with skill development and behaviours that promote financial socialization and financial capacity formation (Willis, 2017). Moreover, developing financial capacity is crucial in the broader context of risk transfer, shifting responsibility from employers to employee-consumers relative to retirement savings accounts (Aprea et al., 2016). This risk is multifaceted and includes inadequate planning, alongside a limited understanding of investment options and their ramifications. In addition to addressing these realities, we seek to prepare students better as they transition to the workforce through an initiative called "skills infusion". In addition to addressing these realities, we seek to better prepare students as they transition to the workforce through an initiative called "skills infusion".

\subsection{Skills infusion and career readiness embedded in learning outcomes}

Skills infusion is a program launched by the campus career centre with funding from the Lilly Endowment. Pairing this program with financial literacy objectives, we seek to facilitate transferable skill formation. Relevant skills include critical thinking, problemsolving, oral, and written communication, teamwork, digital technology, work ethic and professionalism, leadership, career management, and global and intercultural fluency 
(National Association of Colleges and Employers [NACE], 2020). Skills infusion is an instructional strategy designed to align course objectives with NACE (2020) competencies (Asartaa et al., 2014). Teams consisting of faculty, employer/alumni, and career centre representatives meet to understand the connections between skills valued by employers and course content. Senior faculty members facilitate the enhancement of syllabi connecting workplace competencies with course projects, assessments, and other assignments. This strategic initiative connects faculty, alumni, and employers to incorporate skill development in learning objectives and support career readiness.

The desired outcome is students who possess highly valued transferable career skills for future career development. Such skills and competencies are an instructional focus in Personal Finance classes concerned with career readiness skills embedded in course objectives (Ball State University, 2020). Clicker questions and strategies support student development of critical thinking, problem-solving, communication, and teamwork, among other professional career readiness skills.

\subsection{Questions that teach and clickers for increased student engagement}

Utilizing clickers in a large lecture class introduces the concept of letting questions do the teaching (Thomas \& Dougall, 2019), increasing engagement, improving student success and retention metrics (Harvey, 2019). Skills infusion facilitates student skill development, connecting carefully constructed questions, learning objectives, and identified competencies. Harvey (2019) argued, "students showing up to class and campus events is often more than half the battle. Engaging students in meaningful ways using clickers is key to delivering better learning outcomes and improved retention." (p.3)

Identifying engagement through students' expressed interest, motivation to learn, participation, interaction, and progression in large lecture courses is challenging. We recognize inherent limitations embedded in a large class format, including distancing faculty and students, a sense of anonymity, and the need to adopt strategies that promote active learning. Specifically, Nelson and Hauck (2008) described the need for active learning to engage higher-order thinking, with students as active participants rather than passive listeners. Active learning effectively moves students from a low level of student engagement (knowledge and comprehension) to high levels of student engagement (synthesis) depicted in the conceptual relationship with Bloom's Taxonomy, see Figure 2. 
HOLISTICA Vol 12, Issue 2, 2021, pp.49-63

Figure 2 Conceptual Relationship between Bloom's Taxonomy and Student Engagement

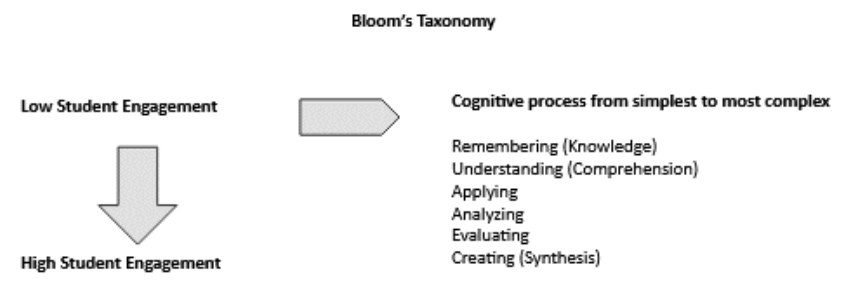

Source: Adapted from V. Bajtelsmit (2020). Engaging students online in your personal finance course. [PowerPoint slides]. https://register.gotowebinar.com/recording/viewRecording /5302996662489949965/912102475666790156/osmcatee@bsu.edu?registrantKey=3368286107 153540621\&type=ABSENTEEEMAILRECORDINGLINK.

\subsection{Improving question construction for student engagement}

Proper clicker question construction is vital for student engagement and is rooted in pedagogy and practicality (Thomas, 2019). Creating prompts in a particular order encourages student participation via clickers during lectures, progressing toward synthesis, and developing critical thinking and analytical skills. Questions serve different purposes, beginning with basic questions requiring students to demonstrate knowledge and understanding of course content. An additional question type invites an analytical choice (i.e., different financing options for a vehicle or home). In this case, students change perspective and engage in a pragmatic and practical application of the course content as they select between two financing options. Finally, questions invite students to reflect, engage and respond. Clicker questions constructed in stages, introduce students to content, reflect on a problem, discuss their solution with a peer, and then respond to a series of multiple-choice options. This intentional movement from the simple to complex reflected in Bloom's Taxonomy (Figure 2), leading students to increase levels of engagement, higher-order learning, synthesis, and critical thinking.

\subsection{Student learning beyond skill development alone}

In addition to developing knowledge and skills, we introduce an alternative understanding of financial literacy because our diverse students represent distinct originating circumstances and social structures that impact financial literacy. Lucey (2018) argued that "a sense of self-worth that occurs independently of financial resources recognizes that people enter life with different degrees of access to financial tools and that worth occurs independently from financial access." (p. 8). Additionally, presenting financial literacy from a sociological point of view, Henchoz (2016) argued that "nevertheless, if the purpose of financial literacy programmes is to empower people fully, then education must not only be conceived as a process of spreading information, instruction and advice. It must also be designated as a process which, to be efficient, must take into account how 
HOLISTICA Vol 12, Issue 2, 2021, pp.49-63

and in which social conditions this information and this instruction are mobilized and translated into practice and well-being." (p. 109)

Such a viewpoint requires an understanding of the role of affect in learning, described in the development of pedagogy (Rendón, 2014), in mathematics (Bieg, 2017; Royer \& BaizeWard, 2020), and an alternative understanding of financial literacy (Lucey, 2018). Likewise, incorporating recent scientific inquiry-curiosity, sociality, emotion, authenticity, and failure from How Humans Learn, addresses classroom encouragement, and leads to improved levels of student success (Eyler, 2018). Through these approaches, we seek to support the development of fiscally informed, financially confident students transitioning to the workplace. Next, we consider specific outcomes and applications of the content in this course.

\section{Outcomes and application}

Students in this course learn about specific personal financial content that includes an affective (interior) view of finance and a skill development (exterior) view that impacts observable behaviour. Beginning from an interior view of financial well-being involves (a) an understanding of personal financial risk tolerance, (b) developing human capital through education, (c) the importance of social capital, and (d) psychological time perspective. Moving to an exterior view, students learn about behaviours and skills to equip them for financial decision-making. These skills include tracking expenses, budgeting, selecting bank accounts, choosing financing terms for autos, credit cards, mortgages, and retirement savings options. Such an approach addresses questions about financial socialization while also providing examples of contextualized, practical problem solving (Koh, 2016). Financial education as a method of financial socialization by design develops individual financial capacity (Willis, 2017).

Furthermore, Henchoz (2016) argued that "financial literacy programmes must become anchored in the relevant social and relational framework, which means they must develop an educational approach going beyond individual skills and shortcomings" (p. 97). Such a holistic approach includes developing financial socialization, skills, and behaviours that Willis (2017) included as non-cognitive and socially constructed components. Gutter et al. (2016) examined college students' financial behaviours related to financial education and concluded that financial attitudes and social learning opportunities are significantly related to financial behaviours. Included in these learning opportunities is forming positive affect and financial confidence toward personal finance.

\subsection{Practical and relevant skill development}

Linking personal finance course content with practical, relevant experiences illustrated by relevant real-life situations results in financially informed citizens. Adaptive, personalized learning tools allow students to build proficiency and use their study time more effectively, which results in the opportunity to engage in higher-order learning through application, analysis, evaluation, and synthesis (Bajtelsmit, 2020). Developing skills and 
HOLISTICA Vol 12, Issue 2, 2021, pp.49-63

improving financial knowledge is crucial because, as Koh (2016) observed, "financial literacy knowledge is meant to be actively applied, and not simply passively retained" ( $p$. 502). Through this pragmatic focus, we introduce practical examples illustrating the impact of positive decision-making, leading students to become financially aware. Classroom examples include various financial products: (a) auto loans, (b) credit scores and their impact on interest rates, (c) debt to income ratio and the ability to borrow, (d) investing and the power of compound interest, and (e) retirement accounts, to name a few. For example, we illustrate the impact of a lower credit score on the decision to finance a car, emphasizing the difference in monthly payments (Table 1).

Table 1 An example of the impact of a lower credit score on auto financing

\begin{tabular}{cccccc}
\hline $\begin{array}{c}\text { Auto loan } \\
\text { amount }\end{array}$ & $\begin{array}{c}\text { Loan } \\
\text { term/duration }\end{array}$ & $\begin{array}{c}\text { Credit } \\
\text { score }\end{array}$ & $\begin{array}{c}\text { Annual } \\
\text { percentage } \\
\text { rate } \%\end{array}$ & $\begin{array}{c}\text { Monthly } \\
\text { payment }\end{array}$ & Difference \\
\hline$\$ 30,000$ & $\begin{array}{l}5 \text { years/60 } \\
\text { payments } \\
5 \text { years/60 } \\
\text { payments }\end{array}$ & High & 5 & 566.14 & \\
& Low & 15 & 713.70 & \\
& & & & $\begin{array}{c}\$ 147.56 \text { per month } \\
\text { or } \$ 8,853.60 \text { over } 5 \\
\text { years }\end{array}$ \\
\hline
\end{tabular}

Source: Authors' synthesis, 2021

We emphasize the pragmatic and practical development of skills and capabilities consistent with the NACE competencies that specifically support students developing problem-solving and critical thinking skills through illustrations like this.

\section{Covid-19 and culturally relevant teaching}

In the spring of 2020, everything about teaching these courses changed. The lockdown imposed by Covid-19 restrictions confined us to remote instruction. We adjusted to the new reality over time using virtual methods (e.g., Webex, Zoom) coupled with video lectures and problem-solving demonstration videos. It is critical to understand this as a time of transition as we moved from an environment that was face-to-face and into a virtual environment incorporating strategies that enabled remote instruction alongside personal contact with students. The transition represented a significant change from previous large lecture settings, as we entered a virtual, remote phase in March 2020. The clicker units we used at that time needed to connect to a base unit in the same room, and therefore did not function remotely. Likewise, the bandwidth demand of large remote meetings in that first 'Covid-19' semester outstripped the university's capacity, resulting in virtual meetings encountering multiple technical problems. Moreover, student dependence on campus-based access to wi-fi and technology further complicated these 
technical issues. Therefore, remote virtual meetings were limited or non-existent for large enrolment courses, further distancing students from faculty and content.

Some face-to-face instruction resumed in the fall 2020 semester, creating challenges for our typical class sections. Covid-19 restrictions meant that a six-foot distance between students was maintained, masks required, and remote Zoom sessions enabled during class sessions. These restrictions effectively impeded our efforts to use clickers, active learning, and create an engaging learning environment. Working under this restrictive environment, we could no longer deploy clickers consistently with previous practice assuming all students met in one room with a base unit collecting responses. The new environment forced us to reconsider how we used clickers and how to engage students actively.

Utilizing clickers in the new format meant acknowledging that the class needed to meet in a mixed format, complicating their adaptation in response to student attendance options. Some students participated via a live Zoom session, and others appeared in the socially distanced face-to-face setting. Student clicker participation was a group of lowstakes assignments with minimal points to encourage participation. For this approach to work, face-to-face participants needed to have a traditional clicker base available to register in class voting. However, a mobile phone app option was available and worked in either a face-to-face or live Zoom session. Polling questions allowed students to respond using either the mobile app (for a smartphone working in both face-to-face and synchronous remote settings) or a traditional hand-held clicker unit (working only in faceto-face sessions with a deployed base unit). Navigating the details of this approach required flexibility; however, student participation remained evenly divided between the remote and face-to-face sessions.

Additionally, for one session restricted to online participation, only the polling feature in Zoom was deployed to track participation because some students lacked access to the mobile app needed to record participation in a remote Zoom session. Finally, adding an introductory formative Kahoot ${ }^{\circledR}$ session previewed the content of the class session in an interactive game for face-to-face and Zoom participants. Underlying these technological adaptations is the expectation that students can access wi-fi at an appropriate bandwidth to allow remote participation, watch videos, and download resources while connecting with peers and faculty via Zoom. Throughout the pandemic, students reported periodic technical difficulties with wi-fi access, in addition to issues using the LockDown Browser proctoring tool for online exams. We acknowledged the need to be sensitive to these student needs from diverse cultural, ethnic, and socioeconomic backgrounds. We also acknowledged that the pandemic surfaced questions about socioeconomic status, equitable access, and the need for culturally responsive teaching. 


\section{Discussion, and Conclusions}

\subsection{Key takeaways}

Large enrolment Personal Finance classes face issues with the physical and affective distancing from students (Denker, 2013), in addition to the potential for a sense of anonymity (Dean et al., 2017). These factors mean making connections necessary for what Rendón (2014) described as a "relationship-centered classroom based on caring, trust, support, and validation" (p. 136), elusive at best. Moreover, we participated in professional development sessions and reading groups during the pandemic focused on supporting equity, inclusion, and diversity as we explored culturally responsive teaching practices. This increased awareness motivated us to become culturally responsive in our teaching, assignment creation, and clicker question construction and enable all students to learn. Culturally responsive teaching uses learners' cultural referents to empower them academically, socially, psychologically, and politically (Ladson-Billings, 1992). We engaged in steps during the pandemic that included: (a) providing information about accessing free wi-fi connections, (b) reviewing videos to ensure captions were available, and (c) focusing on a social and relational framework (Henchoz, 2016), along with a compassionate sense of self-worth (Lucey, 2018) framed in practical examples that belie a restrictive focus on wealth accumulation alone. These actions represented a beginning but did not fully capture the diversity of students or their preferred teaching and learning styles.

Traditional approaches result in a competitive, noncollaborative environment that distances teachers and students (Rendón, 2014), particularly when holistic and cooperative approaches represent student's community of origin (Hooker, 2011; Lundberg et al., 2018). The challenge of meeting the needs of diverse learners is especially prevalent in classrooms where the teachers' instructional styles are incompatible with their students' learning preferences (Donkor, 2011). To acknowledge the range of differences in personal finance competencies in the classroom, we seek to embrace all students in face-to-face, online or hybrid classes, upholding fairness and transforming how we teach, learn, act, and think.

Jenkins (2018) argues that "institutions of higher education have responded to their increasingly diverse student bodies by becoming more diversity-oriented, not only because of the integration of differing voices and beliefs but also due to external pressures from government and society. One of the answers to meeting this challenge is in culturally responsive teaching." (p.15)

We invested our energy and resources to increase student engagement in face-to-face and virtual learning environments as we returned to in-person teaching. Instructors can influence students' engagement, interests, experiences, and connections by reenvisioning assignments and questions, acknowledging diverse backgrounds, and focusing on inclusive and culturally responsive teaching. We acknowledge these nascent efforts are a beginning, representing an avenue of future research that will provide insights into student perceptions and experiences, identifying other approaches and techniques to promote diversity and inclusion in our teaching. In addition to our 
understanding of culturally responsive teaching, we considered how other comparable institutions in our region addressed financial literacy.

Because our course is not unique in higher education, we conducted a review of syllabi from 22 other public colleges and universities in the Midwest. In this review, we did not directly identify another program utilizing the combination of clickers and the NACE competencies. However, other programs may potentially omit such information from course syllabi. Based on our review, we believe this approach is not common and argue for the potential of engaging students in interactive questioning through clickers. We believe our experience, observation, and engagement with this approach supports increased retention and student success in our financial literacy courses. Employing clickers addresses issues that arise in large lecture classrooms where students and faculty are distanced (Denker, 2013), with non-major students in required courses (El-Rady, 2006; Nelson \& Hauck, 2008), and when a sense of anonymity creates a passive learning environment (Dean et al., 2017).

\subsection{Implications}

In these implications, we address the impact of the Covid-19 pandemic on these large lecture classes, our use of clickers, and students. Because of the space limitations and the need to socially distance, these courses continued in an online format, meaning we moved the content, including student interactions, into a remote learning environment. We engaged online tools that provided a sense of interactivity (e.g., Kahoot ${ }^{\circledR}$, Zoom, and a smartphone clicker app) with polling questions. However, the practicality of participating in a large lecture course meant that we needed to integrate these tools with our Learning Management System (LMS). At the same time, we retained as much of the approach in our previous face-to-face sessions as possible.

The move to remote, online learning meant that we needed to modify tests, quizzes, and address the needed accommodations for students with hearing, visual, mental health, and other impairments. Beyond these considerations, we add concerns with students' ability to access technology, deal with military deployment, recognize that we will deal with students in different time zones, and must allow extra time to submit assignments in these circumstances.

Furthermore, we used a variety of class activities to engage students and to help them feel noticed. We solicited consistent feedback from students and explained the adjustments to class structure, modality, and assignments based on students' feedback.

We also recognize that the disruption to our classes emphasized the need for course structure and organization to remain fluid during the Covid-19 pandemic. Furthermore, using the Hyflex approach requires preparation to move from a face-to-face environment into a remote learning environment very rapidly. Adjusting to the new normal of the pandemic required incorporating online digital learning tools to include the content and approximate the face-to-face courses. Moving into the new normal also meant that we consider creating additional lower-stake assessments as we rearrange the number and 
points assigned to high-stake assessments. Additionally, we consider the way we accommodate students with different types of disabilities that include:

- Preparing lecture videos in advance to allow enough time to transcribe and add subtitles;

- When recording live lectures during a face-to-face class for upload into the learning management system (LMS), we must consider extending deadlines for students since it could take several business days to add ADA-compliant subtitles;

- Describing infographic material for visually impaired students;

- Reading the content clearly when recording videos;

- Building additional time to take assessments when dealing with students who have testing anxiety or other learning disability impairments;

- We limit the number of synchronous online or live class meetings to accommodate students.

Despite the Covid-19 disruption in face-to-face classes, using clickers continued to be a viable option to engage students in both face-to-face and remote live Zoom sessions. Students were able to select the use of a smartphone app or the traditional hand-held clicker remote. If students planned to attend some class sessions and participate in live Zoom sessions, they were likely to select the smartphone app (which worked in either a face-to-face or a remote synchronous meeting). If the students elected for the traditional hand-held clicker, they needed to attend face-to-face sessions to record their responses via the base unit. Combining these strategies with a Kahoot ${ }^{\circledR}$ pre-session game, polling in the Zoom app, and carefully constructed polling questions embedded in lectures provided avenues for student participation whether face-to-face or in a synchronous Zoom session. Responding to the distancing imposed by the Covid-19 pandemic, clickers (with some adjustments) engaged students in both virtual and face-to-face class sessions. Future research should consider how financial literacy courses may become more culturally responsive to promote equitable financial education for all students.

\section{References}

Aprea, C., Wuttke, E., Breuer, K., Koh, N. K., Davies, P., Greimel-Fuhrmann, B., and Lopus, J. S. (Eds.), (2016). Financial literacy in the twenty-first century: An introduction to the International Handbook of Financial Literacy. In International Handbook of Financial Literacy. (pp. 1-7) Springer. https://doi 10.1007/978-981-10-0360-8.

Asartaa, C., Hill, A., Meszaros, B. (2014) The features and effectiveness of the Keys to Financial Success curriculum. International Review of Economics Education, 16: 39-50. http://dx.doi.org/10.1016/j.iree.2014.07.002.

Bajtelsmit, V. (2020). Engaging students online in your personal finance course. [PowerPoint slides]. Wiley. https://register.gotowebinar.com/recording/ viewRecording/5302996662489949965/912102475666790156/osmcatee@bsu.edu?regist rantKey=3368286107153540621\&type=ABSENTEEEMAILRECORDINGLINK. 
Ball State University. (2020) Skills Infusion Program Career Center. Accessed June 5, 2020. https://www.bsu.edu/about/administrativeoffices/careercenter/programs-services/skillsinfusion-program.

Barkley, E. F., Cross, K. P., \& Howell-Major, C. (2005). Collaborative learning techniques. JosseyBass.

Beck, T., \& Neiser, B. (2009). Learning and growing: Lessons learned in financial education. Community Investments, (Summer), 11-14.

Bieg, M., Goetz, T., Sticca, F., Brunner, E., Becker, E., Morger, V., \& Hubbard, K. (2017). Teaching methods and their impact on students' emotions in mathematics: An experience-sampling approach. ZDM: The International Journal on Mathematics Education, 49(3): 411-422.

Caldwell, J. E. (2007). Clickers in the large classroom: Current research and best-practice tips. CBE - Life Sciences Education, 6(1): 9-20.

Cheung, G., Wan, K., \& Chan, K. (2018). Efficient use of clickers: A mixed-method inquiry with university teachers. Education Sciences, 8. doi:10.3390/educsci8010031

Dean, T., Lee-Post, A., \& Hapke, H. (2017). Universal design for learning in teaching large lecture classes. Journal of Marketing Education, 39(1): 5-16.

Denker, K. J. (2013). Student response systems and facilitating the large lecture basic communication course: Assessing engagement and learning. Communication Teacher, 27(1): 50-69.

Donkor, A. K. (2011). Higher education and culturally responsive teaching: A way forward. The Journal of Multiculturalism in Education, 7, 1.

El-Rady, J. (2006). To click or not to click: That's the question. Innovate: Journal of Online Education, 2(4), Article 6. https://nsuworks.nova.edu/innovate/vol2/iss4/6/

Eyler, J. R. (2018). How humans learn: The science and stories behind effective teaching. West Virginia University Press.

Gutter, M. S., Copur, Z., Garrison, S. (2016). Do the financial behaviours of college students vary by their state's financial education policies? In C. Aprea, E. Wuttke, K. Breuer, N. K. Koh, P. Davies, B. Greimel-Fuhrmann, and J. S. Lopus, Eds. International Handbook of Financial Literacy. (pp.213 -247). Springer. doi 10.1007/978-981-10-0360-8

Harvey, P. (Macmillanlearning). ( 2019). The power of engagement: Improving drop-fail-withdraw rates and other student retention metrics [Webinar]. https://community.macmillanlearning.com/t5/webinars/webinar-the-power-ofengagement-improving-dfw-rates-and-other/ta-p/10993.

Henager, R., \& Cude, B. J. (2016). Financial literacy and long- and short-term financial behavior in different age groups. Journal of Financial Counseling and Planning, 27(1): 3-19.

Henchoz, C., (2016). Sociological perspective on financial literacy: A critical examination of three assumptions underlying financial literacy programmes. In C. Aprea, E. Wuttke, K. Breuer, N. K. Koh, P. Davis, B. Greimel-Fuhrmann, and J. Lopus (Eds.), International handbook of financial literacy (pp. 97-112). Springer. doi 10.1007/978-981-10-0360-8.

Hooker, D. (2011). Small peer-led collaborative learning groups in developmental math classes at a tribal community college. Multicultural Perspectives, 13: 220-226.

Jenkins, China M. (2018). Educators, question your level of cultural responsiveness. Journal on Empowering Teaching Excellence, 2 (2): 14-23. doi: https://doi.org/10.26077/kttj-v296.

Karger, H. (2015). Curbing the financial exploitation of the poor: Financial literacy and social work education. Journal of Social Work Education, 51, 425-438.

Koh, N. K., (2016). Approaches to teaching financial literacy: Evidence-based practices in Singapore schools. In C. Aprea, E. Wuttke, K. Breuer, N. K. Koh, P. Davis, B. Greimel-Fuhrmann, and J. 
Lopus (Eds.), International handbook of financial literacy (pp. 499-513). Springer. doi 10.1007/978-981-10-0360-8.

Ladson-Billings, G. (1992). Culturally relevant teaching: The key to making multicultural education work. In C. Grant (Ed.), Research and multicultural education: From the margins to the mainstream (pp. $106-121$ ). Routledge.

Lucey, T. (2018). A critically compassionate approach to financial literacy: A pursuit of moral spirit. Education Sciences, 8. doi:10.3390/educsci8040152

Lundberg, T., Conrad, C., Gasman, M., Nguyen, T.-H., \& Commodore, F. (2018). Practices of remedial mathematics students who succeed in college: A case study of developmental math education at Chief Dull Knife College. Review of Higher Education, 42: 61-101.

National Association of Colleges and Employers [NACE], 2020). Career Readiness Defined. Accessed June 12, 2020, from https://www.naceweb.org/career-readiness/competencies/careerreadiness-defined/.

Nelson, M. L., \& Hauck, R. V. (2008). Clicking to learn: A case study of embedding radio-frequency based clickers in an introductory management information systems course. Journal of Information Systems Education, 19(1): 55-64.

Rendón, L. (2014). Sentipensante (sensing/thinking) pedagogy: Educating for wholeness, social justice, and liberation. Stylus.

Retzmann, T. \& Seeber, G. (2016). Financial education in general education schools: A competence model. In C. Aprea, E. Wuttke, K. Breuer, N. K. Koh, P. Davis, B. Greimel-Fuhrmann, and J. Lopus (Eds.), International handbook of financial literacy (pp. 9-24). Springer. doi 10.1007/978-981-10-0360-8.

Sabbaghi, O., Cavanagh S. J, G., \& Hipskind S. J, T. (2013). Service-Learning and leadership: Evidence from teaching financial literacy. Journal of Business Ethics, 118: 127-137. doi:10.1007/s10551-012-1545-6.

Thomas, L., \& Dougall, N. (2019). Let your iClicker questions do the teaching [Webinar]. Macmillan Learning. Accessed June12, 2020. https://community.macmillanlearning.com/t5/ webinars/webinar-let-your-iclicker-questions-do-the-teaching/ta-p/10992.

Vazquez, J., \& Chiang, E. (2020). Know what students know, teach what students need [Webinar]. Macmillan Learning. Accessed April 20, 2020. https://www.flipitecon.com/.

Willis, L. E. (2017). Finance-informed citizens, citizen-informed finance: an essay occasioned by the international handbook of financial literacy. Journal of Social Science Education, 16(4): 1627. 